\title{
Microbial diagnosis of periodontal pathogens
}

\author{
Luisa Miragliotta', Angelica Bertacci², Francesca Cavrini', Paolo Gaibani', Maria Teresa \\ Pellegrino', Carlo Prati' ${ }^{2}$ Vittorio Sambri' \\ 'Dip. di Ematologia e Oncologia “L. e A. Seragnoli”, Sez. Microbiologia \\ ${ }^{2}$ Dip. di Sc. Odontostomatologiche, Università di Bologna, Italy
}

Key Words: periodontal pathogens, microbial diagnosis, periodontal disease

La malattia parodontale: diagnosi microbiologica tradizionale e molecolare

\section{SUMMARY}

\section{Introduction}

Periodontal disease is related to the chronic inflammation involving the supporting structures of the teeth (periodontium). Beginning and progression of disease are closely associated with the presence of anaerobic Gram negative bacteria in the gingival crevice. Because of the complexity of this flora, its identification requires either traditional methods (i.e. microscopy and cultural methods) or molecular approach (PCR, Polymerase Chain Reaction) in order to achieve results that may be useful from a clinical point of view. We have studied the flora from periodontal pockets of $4 \mathrm{I}$ subjects with a clinical diagnosis of periodontitis.

\section{Methods}

The subgingival samples were collected using sterile paper points inserted subgingivally and inoculated onto appropriate plating media: blood agar, kanamycin vancomycin laked blood (KVLB), and NOS medium (New Oral Spirochetes).After incubation in anaerobic environment, a detailed colony description was recorded in particular with regard to size, shape, color, and pigment. The identification was performed by API20 system (bioMérieux). Molecular study was carried out by PCR method, using whole genomic DNA.

\section{Results}

Porphyromonas gingivalis, Prevotella intermedia, Tannerella forsythensis, and Treponema denticola were the most commonly strains isolated.

\section{Conclusions}

Both traditional and molecular approach are needed to identify the bacterial flora associated with periodontal disease. This approach represents an important strategy to either support the clinical diagnosis or control the extent of the disease. Furthermore, the possibility to evaluate the susceptibility pattern of antibiotic resistance among bacterial isolates might be important in view of the new antibiotic resistance recently described for those periodontal bacteria.

\section{INTRODUZIONE}

La malattia parodontale è una patologia infettivoinfiammatoria delle strutture anatomiche di sostegno del dente. Insorgenza e progressione della malattia sono associate a batteri Gram-negativi anaerobi la cui presenza nella tasca gengivale può essere patognomonica dei differenti stadi della malattia. Per identificare questi batteri, alcuni dei quali di difficile coltivazione (per es. Treponema, Tannerella), è fondamentale utilizzare sia procedure tradizionali (esame microscopico-biochimico) che indagini molecolari (PCR, Polymerase Chain Reaction), al fine di ottenere un risultato il più possibile accurato e clinicamente utile. In questo lavoro è stata indagata la flora microbica delle tasche parodontali di 41 individui con diagnosi clinica di parodontopatia, utilizzando sia l'approccio microbiologico tradizionale che quello molecolare.

\section{MATERIALI E METODI}

41 campioni sono stati ottenuti dalle tasche gengivali di soggetti con diagnosi clinica di parodontopatia (5).

L'esame colturale è stato finalizzato alla ricerca di batteri Gram-negativi anaerobi obbligati. A questo scopo sono stati utilizzati i seguenti terreni:

- Terreno NOS selettivo per Treponema denticola, a $37^{\circ} \mathrm{C}$, utilizzato in cappa per anaerobi (ThermoForma model 1025/1029. Anaerobic

\section{Corresponding author: Luisa Miragliotta}

Dipartimento di Ematologia e Oncologia "L. e A. Seragnoli", Sezione Microbiologia,

Via Massarenti, 9 - Bologna, Italy

E-mail: luisamiragliotta@libero.it 
System). Prima di inoculare Treponema denticola è stata verificata la purezza della coltura attraverso l'osservazione di un vetrino con microscopio a campo oscuro (Nikon Eclipse E600). Treponema denticola è stata mantenuta in coltura fino al raggiungimento di una densità di circa $10^{9}$ batteri/ml, tarda fase stazionaria, controllata attraverso conta in microscopio in campo oscuro di diverse diluizioni seriali.

- Terreno Brucella Agar (AS) addizionato di sangue defibrinato di montone al $4 \%$, emina (concentrazione finale $5 \mu \mathrm{g} / \mathrm{ml}$ ) e vitamina $\mathrm{K}$ (concentrazione finale $10 \mu \mathrm{g} / \mathrm{ml}$ ) utilizzato per l'isolamento di Porphyromonas gingivalis.

- Terreno KVLB (Kanamicina Vancomicina Laked Blood) è selettivo per i batteri Gramnegativi. La miscela Kanamicina-Vancomicina è stata addizionata a Brucella Agar contenente 4\% di sangue defibrinato di montone, emina (concentrazione finale $5 \mu \mathrm{g} / \mathrm{ml}$ ) e vitamina $\mathrm{K}$ (concentrazione finale $10 \mu \mathrm{g} / \mathrm{ml}$ ) per facilitare l'isolamento delle differenti specie di Prevotella spp. partendo da prelievi polimicrobici (8). L'associazione dei due antibiotici permette infatti di inibire la maggior parte dei germi Gram-positivi e degli enterobatteri eventualmente presenti.

Dopo incubazione, si è proceduto a valutare:

a. morfologia delle colonie;

b. fluorescenza;

c. pigmentazione;

d. morfologia cellulare mediante colorazione di Gram.

L'identificazione è stata eseguita utilizzando il sistema API 20 A (bioMèrieux), sistema manuale standardizzato che permette di identificare rapidamente i batteri anaerobi dopo 24 ore di incubazione in aerobiosi (2).

\section{Estrazione di DNA}

Il DNA batterico nei campioni studiati è stato estratto con estrattore automatico Easy Mag (bioMerièux). Il processo prevede lisi interna ed eluato finale di DNA di $400 \mu \mathrm{l}$. Il DNA estratto si conserva a $-20^{\circ} \mathrm{C}$ ed è pronto per essere utilizzato per indagine molecolare.

\section{Esame molecolare (PCR)}

Per verificare la presenza dei microrganismi di nostro interesse è stata utilizzata metodica PCR (Polymerase Chain Reaction) tradizionale.

In particolare sono stati utilizzati protocolli specifici per la ricerca di: Porphyromonas gingivalis, Prevotella intermedia, Treponema denticola, Tannerella forsythensis, Enterococcus faecalis.

\section{Elettroforesi su gel di agarosio $1 \%$}

Per verificare la presenza del microrganismo d'interesse si esegue successivamente elettroforesi su gel d'agarosio $1 \%$. Il gel è stato preparato sciogliendo 1 gr di agarosio in TAE $1 \mathrm{X}$ e $5 \mu \mathrm{l}$ di Gel Red. Nei pozzetti del gel sono stati caricati $5 \mu \mathrm{l}$ di marker MassRuler Express DNA Ladder MixReverse e $10 \mu \mathrm{l}$ di amplicone. Il gel è stato fatto correre per circa 10' a 75 Volt e per circa 45' a 100 Volt. Terminata l'elettroforesi, la presenza delle bande sul gel è stata valutata mediante trans illuminatore.

\section{RISULTATI}

L'approccio microbiologico tradizionale ha evidenziato presenza di $P$. gingivalis in $8 / 41$ (19.5\%) pazienti e di $P$. intermedia in 7/41 (17\%) pazienti. L'approccio microbiologico molecolare mediante PCR ha evidenziato la presenza di $T$. denticola in 37/41 (90.2\%) pazienti, P. gingivalis in 36/41 (87.8\%) pazienti, $P$. intermedia in 24/41 (58.5\%) pazienti, T. forsythensis in 15/41 (36.5\%) ed E. faecalis in 0/41 (0\%) pazienti (Figura I). La PCR ha quindi evidenziato la presenza di batteri anaerobi che indicano uno stadio avanzato della malattia.

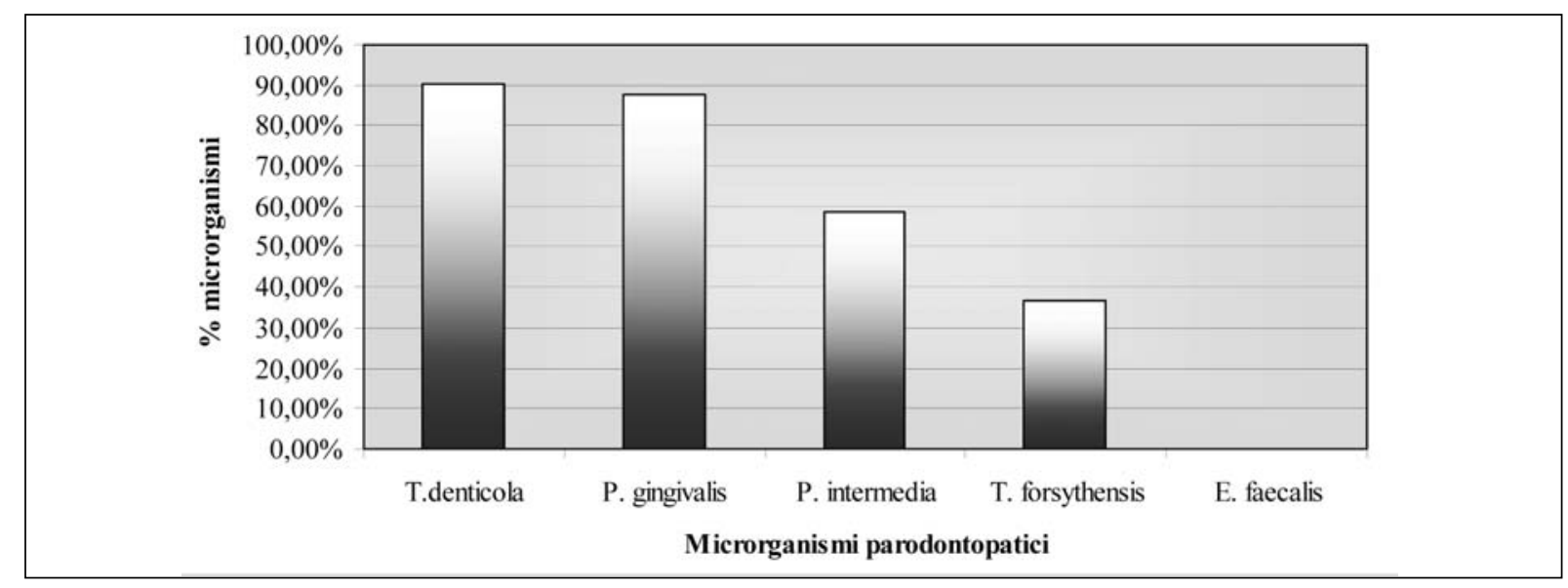

Figura I. Identificazione molecolare di microrganismi parodontopatici (\%) in 4 I pazienti con diagnosi clinica di parodontopatia 


\section{CONCLUSIONI}

La progressione della malattia parodontale, una volta che questa si è instaurata, è continua, con episodi di esacerbazione e remissione (1). Porphyromonas gingivalis, Prevotella intermedia, Tannerella forsythensis sono microrganismi etiopatogeneticamente correlati alla malattia parodontale e il loro isolamento/identificazione è fondamentale per la corretta diagnosi della patologia orale considerata. A questo fine, la diagnosi molecolare risulta particolarmente importante per Treponema denticola, microrganismo di difficile coltivazione la cui presenza si accompagna alle fasi di riesacerbazione della malattia parodontale. Treponema denticola sembra svolgere un ruolo di primaria importanza nella e progressione della malattia parodontale. Questa spirocheta possiede infatti particolari caratteristiche quali citotossicità (9), elevata azione proteolitica $(3,4,6)$, capacità di adesione alle cellule epiteliali ed una motilità che le permettono di ledere il tessuto parodontale ed evadere la risposta da parte dell'ospite (7). In generale considerati, i dati ottenuti indicano come l'approccio diagnostico molecolare sia dotato di sensibilità e specificità significativamente maggiori rispetto all'isolamento e all'identificazione microbiologici tradizionali e quindi particolarmente utili nel supportare la diagnosi clinica. D'altra parte, l'identificazione dei microrganismi etiologicamente correlati alla malattia parodontale può costituire un valido supporto anche alla terapia antibatterica empirico-ragionata, soprattutto alla luce delle variazioni del pattern di sensibilità antibiotica di questi batteri di recente descritte in letteratura (5).

\section{BIBLIOGRAFIA}

1. Corvino E, Gaeta C, Pozzi G, et al. I fattori di virulenza dei patogeni parodontali: Actinobacillus actinomycetemcomitans, Porphyromonas gingivalis, Prevotella intermedia. Giorn It Microbiol Medica Odontoiatrica e Clinica Vol. VI, $\mathrm{N}^{\circ} 1$, p. 40 - 49,2002

2. Downes J, King A, Hardie J, et al. Evaluation of the rapid ID 32A system for identification of anaerobic Gram-negative bacilli, excluding the Bacteroides fragilis group. Clin Microbiol Infect. 5:319-326, 1999

3. Makinen KK, Makinen PL, Syed SA. Purification and substrate specificity of an endopeptidase from the human oral spirochete Treponema denticola ATCC 35405, active on furacryloyl-Leu-Gly-Pro-Ala and bradykinin. J Biol Chem. 267:14285-14293, 1992

4. Makinen KK, Makinen PL, Syed SA. An endo-active proline-specific oligopeptidase from Treponema denticola ATCC 35405: evidence of hydrolysis of human bioactive peptides. Infect. Immun. 62: 4938- 4947, 1994

5. Mosca A, Miragliotta L, Iodice MA, et al. Antimicrobial profiles of Prevotella spp. and Fusobacterium nucleatum isolated from periodontal infections in a selected area of southern Italy. Int $J$ Antimicrob Agents. 30:521-524, 2007

6. Ruby J, Rehani K, Martin M. Treponema denticola activates mitogen-activated protein kinase signal pathways through Toll-like receptor 2._Infect Immun. 75: 5763-8, 2007

7. Sela, MN. Role of Treponema denticola in periodontal diseases. Crit Rev Oral Biol. Med. 12:399-413, 2001

8. Summanen P, Baron JO, Citron DM, et al. Watswords Anaerobic Bacteriology Manual ed.5. Belmont Star Publishing, 1993

9. Uitto VJ, Pan YM, Leung WK, et al. Cytopathic effects of Treponema denticola chymotrypsin- like proteinase on migrating and stratified epithelial cells. Infect. Immun. 63:3401-3410, 1995 